
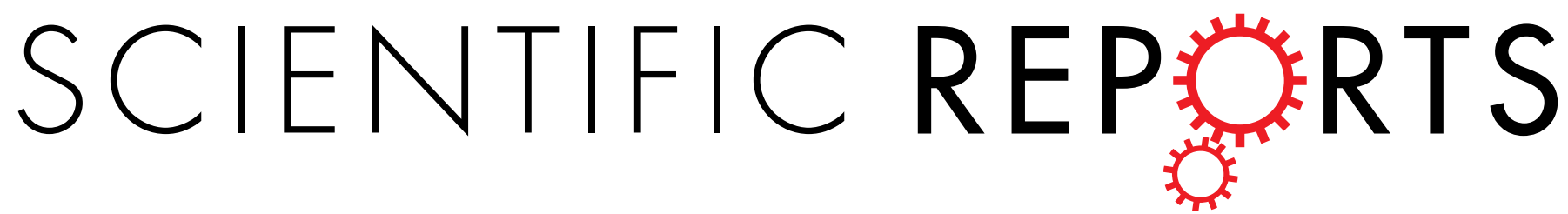

OPEN

\title{
Preparation of Pd supported on La(Sr)-Mn-O Perovskite by microwave Irradiation Method and Its Catalytic Performances for the Methane Combustion
}

Received: 18 September 2015

Accepted: 14 December 2015

\author{
Wei Wang, Fulong Yuan, Xiaoyu Niu \& Yujun Zhu
}

In this work, a series of palladium supported on the $\mathrm{La}_{0.8} \mathrm{Sr}_{0.2} \mathrm{MnO}_{3.15}$ perovskite catalysts ( $\mathrm{Pd} / \mathrm{LSM}-\mathrm{x}$ ) with different $\mathrm{Pd}$ loading were prepared by microwave irradiation processing plus incipient wetness impregnation method and characterized by XRD, TEM, $\mathrm{H}_{2}$-TPR and XPS. These catalysts were evaluated on the lean $\mathrm{CH}_{4}$ combustion. The results show that the $\mathrm{Pd} / \mathrm{LSM}-\mathrm{x}$ samples prepared by microwave irradiation processing possess relative higher surface areas than LSM catalyst. The addition of $\mathrm{Pd}$ to the LSM leads to the increase in the oxygen vacancy content and the enhancement in the mobility of lattice oxygen which play an important role on the methane combustion. The Pd/LSM-3 catalysts with $4.2 \mathrm{wt} \%$ Pd loading exhibited the best performance for $\mathrm{CH}_{4}$ combustion that temperature for $10 \%$ and $90 \%$ of $\mathrm{CH}_{4}$ conversion is 315 and $520^{\circ} \mathrm{C}$.

Natural gas ( $>90 \%$ methane, $\mathrm{CH}_{4}$ ) is promising alternative sources for heat and energy production ${ }^{1}$. The cleaner emission of natural gas engines, i.e., less $\mathrm{NOx}, \mathrm{SOx}$, and particulates compared to diesel engines, is also the merit of natural gas ${ }^{2,3}$. They are widely used for power generation in gas turbines and natural gas vehicles have become an increasingly important. However, the emission of $\mathrm{CH}_{4}$ should be strictly controlled because methane has around 20 times higher greenhouse effect than $\mathrm{CO}_{2}{ }^{4}$. Therefore, it is important to totally oxidize methane and remove as much of the unburned hydrocarbon as possible prior to its release into the atmosphere. The conventional thermal combustion of methane requires very high temperature (up to $1600^{\circ} \mathrm{C}$ ), resulting in production of noxious by-products such as $\mathrm{NOx}^{5}$. The catalytic combustion has been considered as an effective measure to dispose lean methane for pollution abatement as well as energy utilization at low temperature ${ }^{6-9}$.

Perovskite $\left(\mathrm{ABO}_{3}\right)$ is a versatile catalyst which has been used in methane partial oxidation ${ }^{10}$. This can be attributed to its unique crystalline structure, ion mobility, and thermal stability ${ }^{10-12}$. It was generally reported that, among the possible compositions, cobalt and manganese-based solids exhibited much higher activities in B position in the structure ${ }^{13-15}$. Levasseur and Kaliaguine ${ }^{16}$ prepared a series of $\mathrm{LaBO}_{3}(\mathrm{~B}=\mathrm{Co}, \mathrm{Mn}$ and $\mathrm{Fe})$ catalysts by adopting an approach called the "reactive grinding method", and found that the catalytic performance for methanol oxidation followed the sequence $\mathrm{LaMnO}_{3}>\mathrm{LaCoO}_{3}>\mathrm{LaFeO}_{3}$. Most of the studies on perovskite are based on lanthanum placed in A-position ${ }^{17}$. It has been proven that among the $\mathrm{ABO}_{3}$, the $\mathrm{La}_{1-\mathrm{x}} \mathrm{Sr}_{\mathrm{x}} \mathrm{MO}_{3}(\mathrm{M}=\mathrm{Co}$, $\mathrm{Mn} ; \mathrm{x}=0-0.4)$ materials show the excellent catalytic performance for the methane combustion ${ }^{18-20}$.

Palladium-based catalysts are currently recognized as the most active in the total combustion of methane and other hydrocarbons, and boast the largest use in the catalytic cleanup of emissions from stationary sources under lean-burn conditions at low temperature ${ }^{21,22}$. As has been found in several studies, there is a number of factors influencing the Pd catalytic activity, the type of palladium precursors ${ }^{23}$, the state of the active Pd component (the nature of the active sites) ${ }^{24}$, and the nature of the support ${ }^{25-27}$. In particular, it is known that the oxidation state of $\mathrm{Pd}$ is very important for catalytic methane combustion. Diannan et al. ${ }^{28}$ suggested that the active phase of the $\mathrm{Pd} / \mathrm{Al}_{2} \mathrm{O}_{3}$ catalyst is $\mathrm{PdO}$ or mixed $\mathrm{Pd}^{0} / \mathrm{PdO}$. R.J. Farrauto et al. ${ }^{29}$ considered that at least two distinct oxygen/ palladium species are present in palladium oxide supported on alumina decomposes. Once the temperature of the 


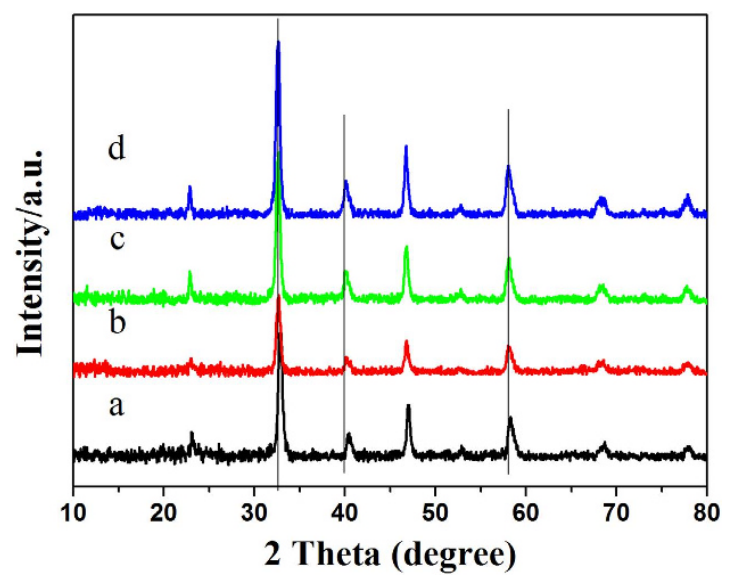

Figure 1. XRD patterns of LSM and Pd/LSM-x catalysts (a) LSM, (b) Pd/LSM-1, (c) Pd/LSM-2, (d) Pd/LSM-3.

catalyst exceeds $800^{\circ} \mathrm{C}$ and palladium metal is formed it does not re-oxidize until the temperature falls to about $650^{\circ} \mathrm{C}$. In fact, it can be confirmed that the existence of a threshold temperature level for the catalyst activation corresponds to the temperature required for the decomposition of $\mathrm{Pd}$ oxide species and consequent segregation of metallic Pd onto the surface of the catalyst ${ }^{30}$.

Activity and stability of a catalyst are strongly related to its properties, which are determined by the preparation method adopted. The traditional methods e.g., sol-gel ${ }^{31}$, citrate $^{32}$, solid-state reaction ${ }^{33}$ and co-precipitation ${ }^{34}$, involve in high-temperature and long time. This could damage to the environment and waste materials. In the late $1980 \mathrm{~s}$, microwave assisted synthesis was introduced into the field of materials ${ }^{35}$. It has been reported that the perovskite of uniform particle size and a better oxidation activity can be attained in microwave route ${ }^{36}$. In our previous work, we had investigated the preparation of La-Mn-O perovskite catalyst by microwave irradiation method (MIM) and sol-gel method, and found that the La-Mn-O perovskite catalyst prepared by microwave method showed much better performance for methane combustion ${ }^{37}$. In this study, we investigated the preparation and characterization of $\mathrm{La}_{0.8} \mathrm{Sr}_{0.2} \mathrm{MnO}_{3.15}$ (LSM) perovskite catalyst by microwave irradiation method and its application used as support to obtained $\mathrm{Pd} / \mathrm{LSM}$ catalysts by combining the incipient wetness impregnation and microwave irradiation method. The catalytic performances of the Pd/LSM catalysts and the role of Pd species were studied for methane combustion.

\section{Results and Discussion}

XRD characterization. The LSM and Pd/LSM-x $(x=1,2$ and 3) catalysts with different Pd loadings were prepared by microwave irradiation method. The XRD patterns of the LSM and Pd/LSM-X catalysts are shown in Fig. 1 . All of the Bragg diffraction peaks in the $2 \theta$ range of $10-80^{\circ}$ could be well indexed. For the signal of LSM intensive and sharp diffraction peaks at $2 \theta$ values of $23.07,32.85,40.35,46.97,52.72,58.20,68.64$ and $77.81^{\circ}$ observed here can be primarily attributed to $\mathrm{LaMnO}_{3.15}$ perovskite-type oxides (JCPDS 50-0298). The diffraction peaks of Pd/LSM-x located at about $2 \theta$ values of $22.93,32.58,40.13,46.75,52.32,58.07,68.11$ and $77.67^{\circ}$ shift slightly toward lower $2 \theta$ degree compared with the LSM. Table S1 lists the $2 \theta$ values of the diffraction peaks for the LSM and $\mathrm{Pd} / \mathrm{LSM}$-x catalysts. It is nearly identical to their corresponding perovskite $\mathrm{La}_{0.8} \mathrm{Sr}_{0.2} \mathrm{MnO}_{3}$ structures (JCPDS 53-0058), indicating part of the oxygen was reduced under the presence of ethylene glycol (EG). It could be assigned to the removal of the nonstoichiometric excess oxygen in the prepared process by MIM using EG. For the patterns of the Pd/LSM-x catalysts, no obvious diffraction peaks of PdO or Pd were observed, suggesting the high dispersion of palladium with the low Pd loading. The XRD results can clearly confirm that the way of microwave synthesis used in this work was sufficient to crystallize the precursor into the perovskite structure during a very short time in the synthesis step. In addition, the intensities of diffraction peaks increase with the addition of $\mathrm{Pd}$ amount, suggesting the increase in the crytallinity. However, the average particle sizes calculated from XRD patterns based on Scherrer's equation are 15.0, 15.8, 16.0 and 16.1 nm for LSM Pd/LSM-1, Pd/LSM-2 and Pd/ LSM-3, respectively, which indicates that the average particle sizes increase slightly with the addition of Pd.

The Pd content is $1.2 \%, 2.6 \%$ and $4.2 \%$ for the Pd/LSM-1 Pd/LSM-2 and Pd/LSM-3 by ICP-AES analysis, respectively (Table 1). The BET surface areas of the LSM and Pd/LSM-x catalysts are in the range of $15-41 \mathrm{~m}^{2} / \mathrm{g}$ with different error shown in Table 1. Compared with the LSM, it's noted that the supporting Pd on the LSM perovskite oxides has a positive effect on surface areas. The BET surface area is $15 \mathrm{~m}^{2} \cdot \mathrm{g}^{-1}$ for the LSM, while it increased from $19 \mathrm{~m}^{2} \cdot \mathrm{g}^{-1}$ to $41 \mathrm{~m}^{2} \cdot \mathrm{g}^{-1}$ with the Pd amount for the Pd/LSM-x catalysts, which indicates MIM using EG may induce surface reconstruction that would be able to enhance the specific surface area by the interactions between the Pd and LSM.

TEM characterization. The TEM and elemental micrograph were conducted to investigate the morphology of the Pd/LSM-x using the Pd/LSM-2 as sample displayed in Fig. 2. From Fig. 2a, it is difficult to distinguish the $\mathrm{Pd}$ and LSM phase in the low resolution TEM, which may be attributed to their similar contrast in the TEM image and Pd good dispersion on the LSM. In the HRTEM of the Pd/LSM-2 sample given in Fig. 2b, there were clear lattice fringes, revealed that Pd nanoparticles in the catalyst were bound with (100) facets, and (111) facets, and 


\begin{tabular}{|c|c|c|c|c|c|c|c|c|}
\hline \multirow[b]{2}{*}{ Catalyst } & \multirow{2}{*}{$\begin{array}{c}\text { BET surface } \\
\text { area }\left(\mathbf{m}^{2} \cdot \mathbf{g}^{-1}\right)\end{array}$} & \multirow{2}{*}{$\begin{array}{c}\text { Pd content } \\
\text { wt } \%\end{array}$} & \multicolumn{6}{|c|}{ Date of $\mathrm{H}_{2}$-TPR $(\mathrm{mmol} / \mathrm{g})$} \\
\hline & & & $\mathrm{T}_{1}^{\mathrm{b}}\left({ }^{\circ} \mathrm{C}\right)$ & $A_{1}{ }^{c}(\mathrm{mmol} / \mathrm{g})$ & $\mathrm{T}_{2}^{\mathrm{b}}\left({ }^{\circ} \mathrm{C}\right)$ & $\mathrm{A}_{2}{ }^{\mathrm{d}}(\mathrm{mmol} / \mathrm{g})$ & $\mathrm{T}_{3}{ }^{\mathrm{b}}\left({ }^{\circ} \mathrm{C}\right)$ & $\mathrm{A}_{3}{ }^{\mathrm{d}}(\mathrm{mmol} / \mathrm{g})$ \\
\hline LSM & $15 \pm 0.6$ & - & - & - & $326 / 426$ & $0.36 / 2.04$ & 782 & 0.47 \\
\hline Pd/LSM-1 & $19 \pm 1.1$ & 1.2 & 55 & $7.4 \times 10^{-3}$ & 309 & 0.43 & 765 & 0.47 \\
\hline $\mathrm{Pd} / \mathrm{LSM}-2$ & $21 \pm 0.8$ & 2.6 & 59 & $3.7 \times 10^{-2}$ & 305 & 0.46 & 766 & 0.47 \\
\hline $\mathrm{Pd} / \mathrm{LSM}-3$ & $41 \pm 1.2$ & 4.2 & 59 & $4.3 \times 10^{-2}$ & 261 & 0.50 & 766 & 0.47 \\
\hline
\end{tabular}

Table 1. Physico-chemical properties of the catalysts. ${ }^{\mathrm{a}} \mathrm{Chemical}$ compositions determined by the ICP technique. ${ }^{b}$ The peaks position in $\mathrm{H}_{2}$-TPR. ${ }^{c}$ Released $\mathrm{H}_{2}$ based on quantitative analysis of $\mathrm{H}_{2}-\mathrm{TPR}$ profiles. ${ }^{\mathrm{d}}$ The data of $\mathrm{H}_{2}$ consumption in $\mathrm{H}_{2}$-TPR profiles.

the (100) and (111) fringes in the spherical nanoparticles exhibited periods of 1.94 and $2.28 \AA$, respectively, as expected for the lattice spacing of face-centered cubic $(\mathrm{fcc}) \mathrm{Pd}^{38}$. Meanwhile, it is found that the lattice spacings of nanoparticle is $2.63 \AA$, which are indexed as the (101) plane of tetragonal $\mathrm{PdO}^{39}$. The EDX spectrum of the Pd/ LSM-2 (Fig. 2c) exhibits the presence of strong signals of $\mathrm{La}, \mathrm{Sr}, \mathrm{Mn}, \mathrm{O}$ and Pd elements. The mapping results of the Fig. $2 \mathrm{~d}$ zone are presented in Fig. $2 \mathrm{e}-\mathrm{i}$ in which the distributions of $\mathrm{La}, \mathrm{Sr}, \mathrm{Mn}, \mathrm{O}$ and $\mathrm{Pd}$ elements are the very same. It indicates that the Pd element is evenly dispersed among $\mathrm{La}, \mathrm{Sr}, \mathrm{Mn}$ and $\mathrm{O}$ elements. Figure $\mathrm{S} 1$ show the results of TEM for the Pd/LSM-1 and Pd/LSM-3, which is similar to that of Pd/LSM-2. Thus, it is difficult to measure accurately the Pd particle size and their distributions based on the above reasons. The particle size Pd species was evaluated in range of $8-20 \mathrm{~nm}$ and the mean particle size is about $12 \pm 2 \mathrm{~nm}$ based the TEM images. TEM results show that the Pd supported on LSM catalysts were successfully synthesized by microwave method, and in which there are metallic Pd and PdO phase.

$\mathrm{H}_{2}$-TPR characterization. To investigate the reducibility of the LSM and Pd/LSM-x catalysts, $\mathrm{H}_{2}-\mathrm{TPR}$ was performed and shown in Fig. 3. As is evident from the results in Fig. 3 and a quantitative analysis is summarized in Table 1 . The LSM catalyst shows three hydrogen uptake peaks. The first peak shows the hydrogen uptake between 270 and $360^{\circ} \mathrm{C}$ with the peak presented at $333^{\circ} \mathrm{C}$. According to the literature ${ }^{37}$, the first peak for the LSM is attributed to the reduction of a fraction of oxygen adsorbed on the surface of the catalysts. The second peak at $426^{\circ} \mathrm{C}$ can be seen obviously in the $\mathrm{H}_{2}$-TPR curve for the LSM catalyst. To obtain the detailed information about the reduction process, the LSM sample after reduction at $500^{\circ} \mathrm{C}$ was characterized by XRD. According to the results shown in Figure S2, the LSM sample after reduction became a phase of $\mathrm{LaMnO}_{3}$ perovskite oxide. Thus, the reduction peak at $427^{\circ} \mathrm{C}$ for LSM should be assigned to the reduction of $\mathrm{Mn}^{4+}$ to $\mathrm{Mn}^{3+}$ accompanying the reduction of the nonstoichiometric oxygen ${ }^{12,22,37}$. The third reduction peak of the LSM sample is in a wide range from $710^{\circ} \mathrm{C}$ to $850^{\circ} \mathrm{C}$, which is ascribed to the reduction of $\mathrm{Mn}^{3+}$ to $\mathrm{Mn}^{2+12,22,37,40}$. The Pd/LSM-x catalysts show only one wide peak in the low temperature region between 209 and $470{ }^{\circ} \mathrm{C}$, which can be attributable to the reduction of oxygen adsorbed on the catalysts surface and a few amount of $\mathrm{Mn}^{4+}$. Similar to LSM sample, the $\mathrm{Pd} / \mathrm{LSM}$-x sample also shows a main reduction peak from $700^{\circ} \mathrm{C}$ to $870^{\circ} \mathrm{C}$, which can also be attributable to the reduction of lattice oxygen corresponding the reduction of $\mathrm{Mn}^{3+}$. Moreover, each of the $\mathrm{Pd} / \mathrm{LSM}-\mathrm{x}$ samples at below $100^{\circ} \mathrm{C}$ has a negative peak, indicating the presence of metal Pd. In $\mathrm{H}_{2}-\mathrm{TPR}$, metal Pd can absorb a certain mount of hydrogen at low temperature, and then the adsorbed $\mathrm{H}_{2}$ will be released with the increase in the temperature. It is noticed that the released $\mathrm{H}_{2}$ amount increases with the Pd loading shown in Table 1 . The reductive temperature over the $\mathrm{Pd} / \mathrm{LSM}-\mathrm{x}$ catalysts and the $\mathrm{H}_{2}$ consumption amount of the referred peak were also gathered in Table 1. The reduced temperature for the low temperature reduced peak is $326,309,305$ and $261^{\circ} \mathrm{C}$ for the LSM, Pd/LSM-1, Pd/LSM-2 and Pd/LSM-3 catalysts, respectively. From the above results, it is clearly seen that the adsorbed oxygen of the Pd/LSM-x samples can be reduced at a much lower temperature than that of the LSM sample, meanwhile, the reduced temperature decreases with the increase in the Pd loading amount. It could be explained that the reduction of the support is advantage by the $\mathrm{H}_{2}$-spillover from metallic Pd. In addition, the $\mathrm{H}_{2}$ consumption amount of the first reduced peak increase from $0.36,0.43,0.46 \mathrm{mmol} / \mathrm{g}$ to $0.50 \mathrm{mmol} / \mathrm{g}$ for LSM, Pd/ LSM-1, Pd/LSM-2 and Pd/LSM-3 catalysts, suggesting the increase in the number of oxygen vacancy with the Pd loading. Compared with the LSM, the reduced temperature for lattice oxygen also shift from $782^{\circ} \mathrm{C}$ to $766^{\circ} \mathrm{C}$ for the $\mathrm{Pd} / \mathrm{LSM}$ samples, which indicates the mobility of lattice oxygen is enhanced for the Pd/LSM samples.

$\mathrm{O}_{2}$-TPD characterization. Figure 4 shows the $\mathrm{O}_{2}$-TPD profiles of the LSM and Pd/LSM-x catalysts. In the $\mathrm{O}_{2}$-TPD profiles of the LSM, there are two desorption peaks with a weak at low temperature and a strong at high temperature. The weak low temperature peak at $375^{\circ} \mathrm{C}$ is assigned to the desorption of the adsorbed oxygen on the oxygen vacancies, and the high temperature peak at $848^{\circ} \mathrm{C}$ is attributed to the desorption of the lattice oxygen ${ }^{12,22}$. Compared with the LSM, the oxygen desorption show a wide peak from $100^{\circ} \mathrm{C}$ to $800^{\circ} \mathrm{C}$ for each of $\mathrm{Pd} / \mathrm{LSM}$ samples. The low-temperature peak in the temperature range of $50-450^{\circ} \mathrm{C}$ is related to desorption of adsorbed oxygen on the surface of the catalysts. These results indicate that oxygen vacancies exist on the surface of both Pd/LSM-x and LSM. Pd/LSM-3 and LSM samples in the temperature of 550-900 ${ }^{\circ} \mathrm{C}$, it is ascribed to the oxygen from crystal lattice of non-stoichiometric oxygen and reduction of manganese ${ }^{12,22}$. The Pd/LSM-x catalysts show a broad $\mathrm{O}_{2}$ desorption peak in the temperature range of $50-500^{\circ} \mathrm{C}$, and $\mathrm{Pd} / \mathrm{LSM}-3$ sample the desorption temperature for lattice oxygen also shift from $848^{\circ} \mathrm{C}$ to $659^{\circ} \mathrm{C}$ compared with the LSM. It can be deduced that the mobility of lattice oxygen was increased. It is quite consistent with the results of the TPR. 

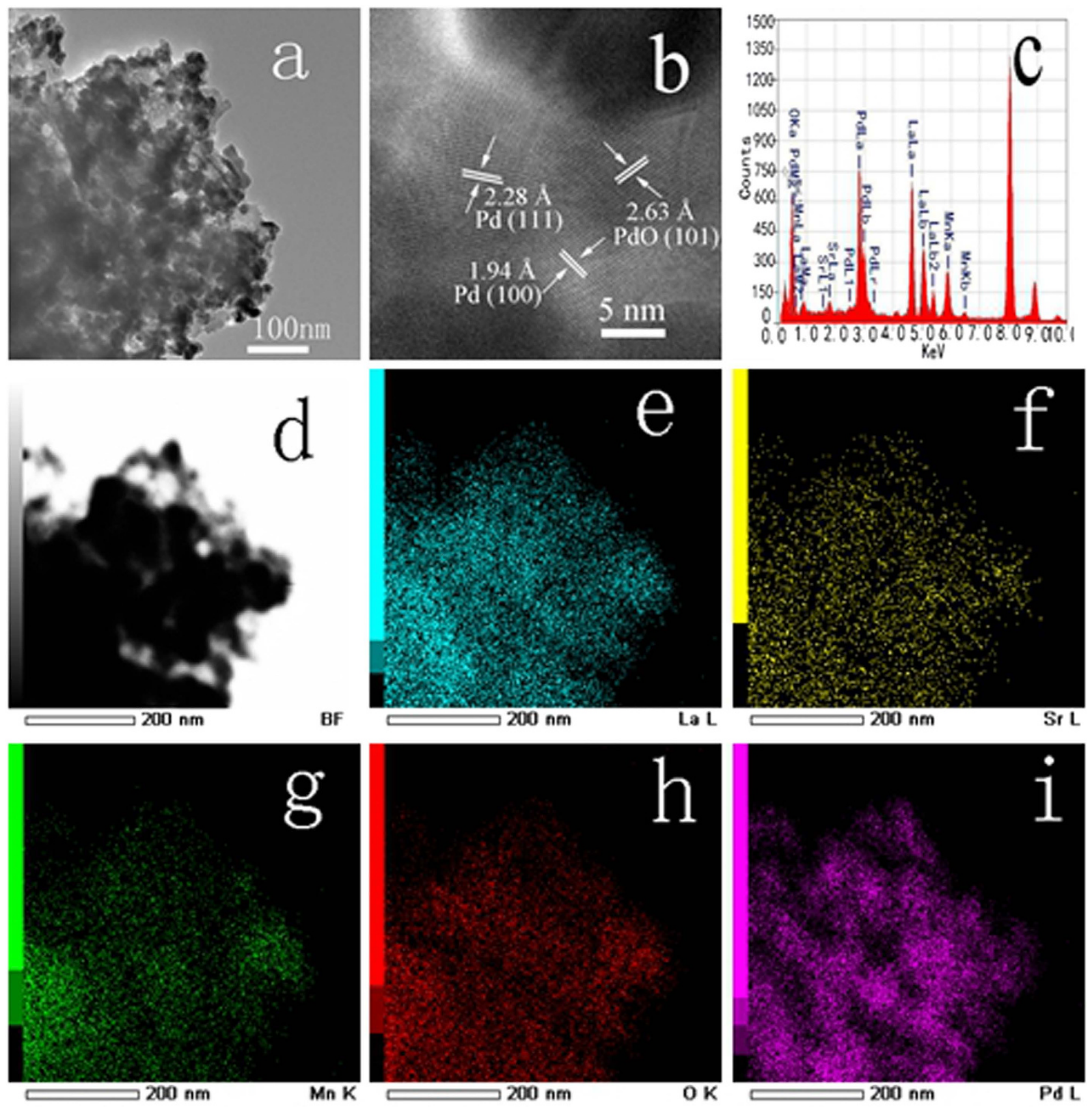

Figure 2. TEM images (a,b) at increasing magnifications of Pd/LSM-2 sample. Also shown are EDX mapping results $(\mathbf{d}-\mathbf{i})$ of Pd/LSM-2.

XPS characterization. XPS is an efficient technique for probing the surface element compositions and surface species of a catalyst. Figure $5 \mathrm{~A}$ presents the results of curve-fitting for $\mathrm{Pd} 3 \mathrm{~d}_{5 / 2}$ spectra. The binding energy at $334.4-334.9 \mathrm{eV}$ could be assigned to $\mathrm{Pd}^{0}$ species. The binding energy located from 335.2 to $335.6 \mathrm{eV}$ represents the fraction of $\mathrm{Pd}$ in the +2 oxidation state. It is noteworthy that the binding energy shifts to low value with the increase in the Pd loading. Such phenomenon is likely to be due to an interaction between Pd and the LSM perovskite. For the sake of clarity, the surface concentrations of both $\mathrm{Pd}^{2+}$ and $\mathrm{Pd}^{0}$ species are provided as the ratio of $\mathrm{Pd}^{2+}$ to $\mathrm{Pd}^{0}\left(\mathrm{Pd}^{2+} / \mathrm{Pd}^{0}\right)$. Table 2 reports the XPS results in terms of relative concentrations of main surface elements. The value of $\mathrm{Pd}^{2+} / \mathrm{Pd}^{0}$ decreases from 1.4 for $\mathrm{Pd} / \mathrm{LSM}-3$ to 1.0 for $\mathrm{Pd} / \mathrm{LSM}-1$. It is proportionally more pronounced in the case of Pd/LSM-1 catalyst with lower Pd loading than Pd/LSM-3 sample. Pd is mainly present in all $\mathrm{Pd} / \mathrm{LSM}-\mathrm{x}$ samples as ionic $\mathrm{Pd}^{0}$ and a fraction of $\mathrm{Pd}^{2+}$.

The Mn2p spectrum reveals three components with binding energy of the Mn2 $\mathrm{p}_{3 / 2}$ electrons shown in Fig. 5B. The binding energies in the range of 641.5-642.5 and 640.2-641.3 eV are attributed to the surface $\mathrm{Mn}^{4+}$ and $\mathrm{Mn}^{3+}$ species, respectively, and the binding energy at $643.6-644.5 \mathrm{eV}$ belongs to the satellite peak ${ }^{37}$. The amount of $\mathrm{Mn}^{4+}$ and $\mathrm{Mn}^{3+}$ species was analyzed wit the deconvolution obtained by fitting Gaussian peaks after Shirley-ackground subtraction (Table 2). The ratio of $\mathrm{Mn}^{4+}$ to $\mathrm{Mn}^{3+}$ species is 1.6 for the LSM sample, however, it decreases to 1.1, 0.91 and 0.87 for the Pd/LSM-1, Pd/LSM-2 and Pd/LSM-3 samples, respectively. It is clear that the amount of 


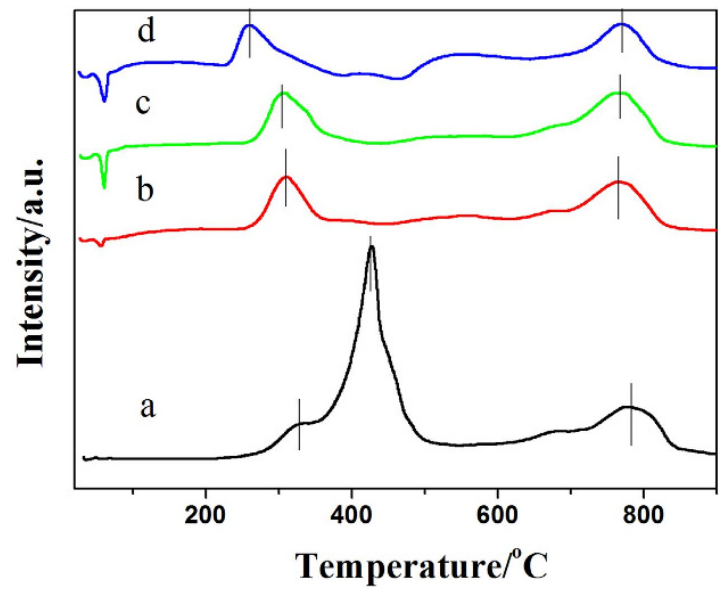

Figure 3. $\mathrm{H}_{2}$-TPR profiles of (a) LSM, (b) Pd/LSM-1, (c) Pd/LSM-2, (d) Pd/LSM-3.

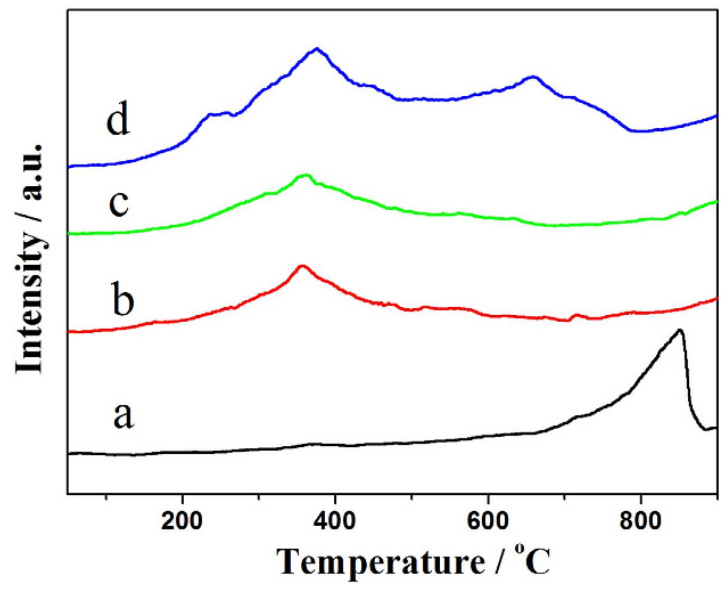

Figure 4. $\mathrm{O}_{2}$-TPD profiles of (a) LSM, (b) Pd/LSM-1, (c) Pd/LSM-2, (d) Pd/LSM-3.

$\mathrm{Mn}^{4+}$ on the surface of the Pd/LSM-x samples is lower than that of the LSM sample, suggesting the $\mathrm{Mn}^{4+}$ is reduced partly by ethylene glycol in the synthesis process with the addition of Pd. This phenomenon is consistent with the results of the $\mathrm{H}_{2}$-TPR and XRD results.

Figure $5 \mathrm{C}$ gives the O1s spectra of the LSM and Pd/LSM-x catalysts. In the XPS spectrum of O1s, the peaks located at about 531 and $529 \mathrm{eV}$ are attributed to adsorbed oxygen on the oxygen vacancy $\left(\mathrm{O}_{\text {ads }}\right)$ and lattice oxygen $\left(\mathrm{O}_{\text {lat }}\right)$, respectively ${ }^{40}$. The variations in the amount of $\mathrm{O}_{\text {ads }}$ and $\mathrm{O}_{\text {lat }}$ for the $\mathrm{O} 1 \mathrm{~s}$ peak were observed. The ratio of $\mathrm{O}_{\text {ads }}$ to $\mathrm{O}_{\text {lat }}$ on the surface of the LSM sample is 1.9, however, it is much higher six times for the Pd/LSM-X samples than that of the LSM sample. Moreover, the surface $\mathrm{O}_{\mathrm{ads}}$ species concentration (Table 2) decreases in the order of $\mathrm{Pd} / \mathrm{LSM}-3>\mathrm{Pd} / \mathrm{LSM}-2>\mathrm{Pd} / \mathrm{LSM}-1$. The results indicate that the $\mathrm{Pd} / \mathrm{LSM}-\mathrm{x}$ samples possess much larger amount of oxygen vacancy. It is in consistence with the results observed in our previous studies of the $\mathrm{H}_{2}$-TPR and $\mathrm{O}_{2}$-TPD.

Catalytic combustion of methane. The catalytic performances of the LSM and Pd/LSM-x catalysts were investigated as a function of reaction temperature in the range of $300-550^{\circ} \mathrm{C}$ for methane combustion and presented in Fig. 6 and Figure S3. It is worth pointing out that $\mathrm{CH}_{4}$ was completely oxidized to $\mathrm{CO}_{2}$ and $\mathrm{H}_{2} \mathrm{O}$ over all the samples, and no other incomplete oxidation products such as $\mathrm{CO}$ were detected in the catalytic system. The results showed that each catalyst displayed an S-shaped activity profile. The methane conversion increased with the temperature, and the Pd/LSM-x catalysts performed much better than the LSM catalyst. It is convenient to compare the catalytic activities of the samples by using the reaction temperature at the methane conversion of $10 \%, 50 \%$ and $90 \%$ that are donated as $\mathrm{T}_{10 \%}, \mathrm{~T}_{50 \%}$ and $\mathrm{T}_{90 \%}$ (Table S2). It is found that the catalytic performance decreased in the sequence Pd/LSM-3 $>$ Pd/LSM-2 $>$ Pd/LSM-1 > LSM. Obviously, the Pd/LSM-3 catalyst performed the best activity among these catalysts, giving $\mathrm{T}_{10 \%}$ and $\mathrm{T}_{50 \%}$ of 314 and $440^{\circ} \mathrm{C}$, respectively, which were much lower by 84 and $45^{\circ} \mathrm{C}$ than others (Table S2). The activities were also measured over the Pd/LSM with 5.1\% Pd amount (denoted Pd/LSM-4) displayed in Figure S4. Compared with the Pd/LSM-3 with 4.2\% Pd content, it can be seen that the methane conversion was not significantly increased with the increase in the Pd content from $4.2 \%$ to $5.1 \%$. Thus, the Pd/LSM catalyst with much higher Pd amount has been investigated in this study. 

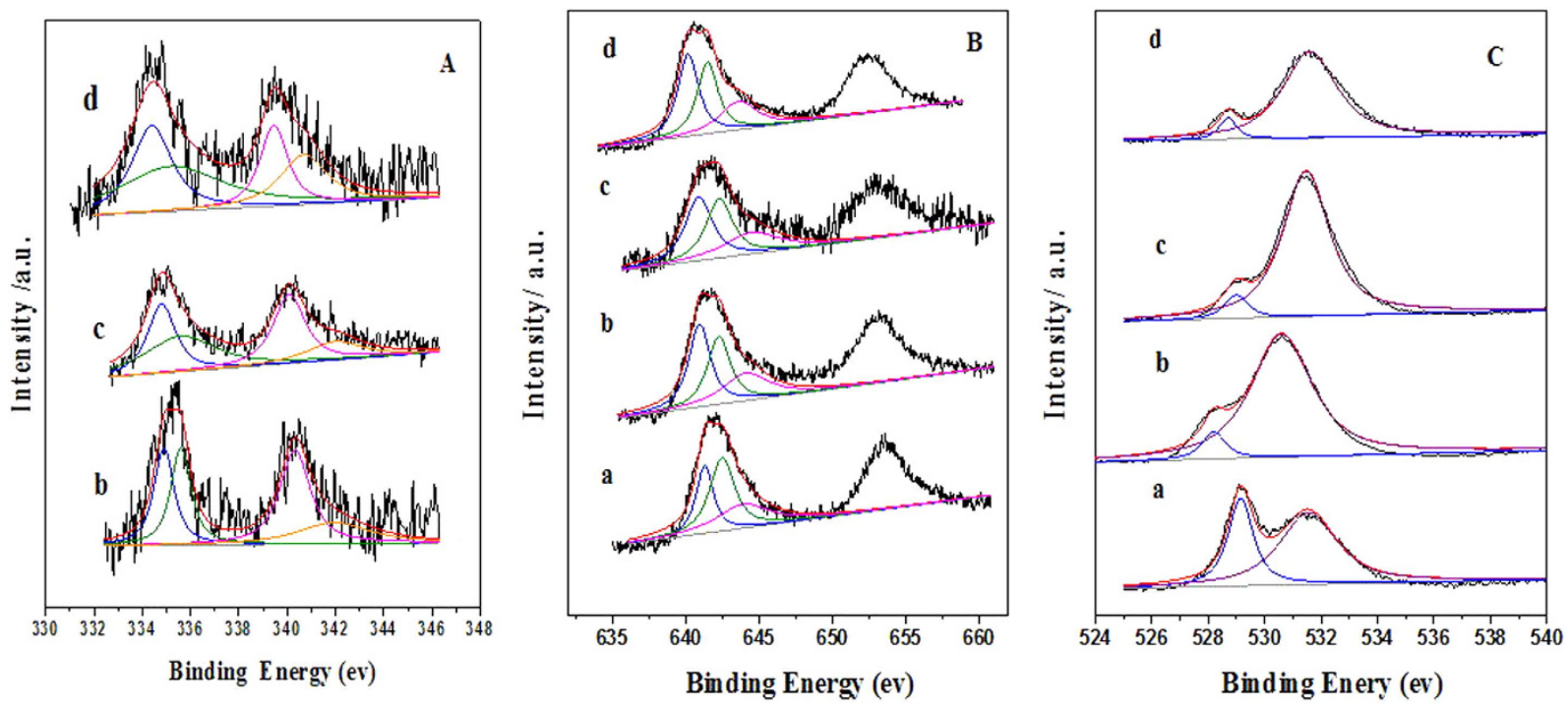

Figure 5. XPS spectra and curve-fitting for $L S M$ and Pd/LSM-x catalysts $(\mathbf{A}) \mathrm{Pd}_{3} \mathrm{~d}_{5 / 2} ;(\mathbf{B}) \mathrm{Mn} 2 \mathrm{p}_{3 / 2} ;$ (C) O1s; (a) LSM; (b) Pd/LSM-1; (c) Pd/LSM-2; (d) Pd/LSM-3.

\begin{tabular}{|l|c|c|c|c|c|c|c|c|c|}
\hline \multirow{2}{*}{ Catalyst } & \multicolumn{3}{|c|}{$\mathbf{P d ~ 3 d}_{\mathbf{5} / \mathbf{2}}$} & \multicolumn{3}{c|}{$\mathbf{M n}_{\mathbf{2}} \mathbf{p}_{\mathbf{3} / \mathbf{2}}$} & \multicolumn{3}{|c|}{$\mathbf{O}_{1 \mathrm{~s}}$} \\
\cline { 2 - 10 } & $\mathbf{P d}^{\mathbf{0}}$ & $\mathbf{P d}^{2+}$ & $\mathbf{P d}^{2+} / \mathbf{P d}^{\mathbf{0}}$ & $\mathbf{M n}^{3+}$ & $\mathbf{M n}^{4+}$ & $\mathbf{M n}^{4+} / \mathbf{M n}^{3+}$ & $\mathbf{O}_{\text {lat }}$ & $\mathbf{O}_{\text {ads }}$ & $\mathbf{O}_{\text {ads }} / \mathbf{O}_{\text {lat }}$ \\
\hline LSM & - & - & - & 641.3 & 642.5 & 1.6 & 529.1 & 531.6 & 1.9 \\
\hline Pd/LSM-1 & 334.9 & 335.6 & 1.0 & 641.0 & 642.3 & 1.1 & 528.4 & 530.6 & 11.7 \\
\hline Pd/LSM-2 & 334.8 & 335.6 & 1.3 & 460.9 & 642.3 & 0.91 & 529.0 & 531.5 & 12.5 \\
\hline Pd/LSM-3 & 334.4 & 335.2 & 1.4 & 640.2 & 641.5 & 0.87 & 528.7 & 531.6 & 12.7 \\
\hline
\end{tabular}

Table 2. XPS data of the LSM and Pd/LSM-x catalysts.

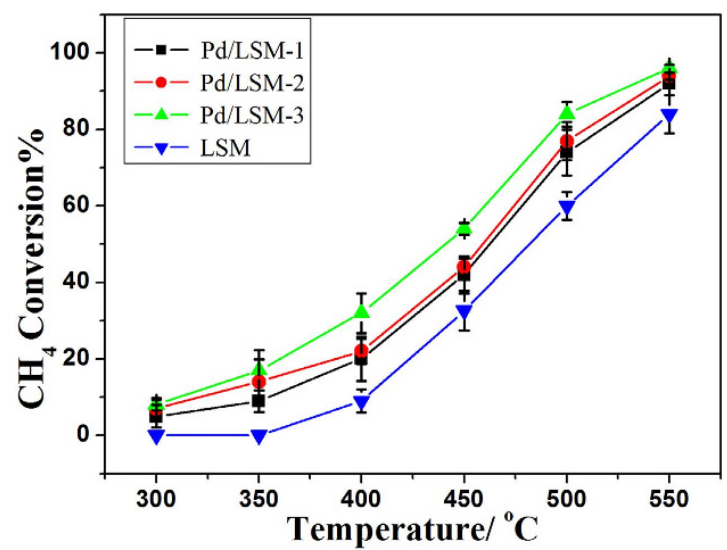

Figure 6. conversion of $\mathrm{CH}_{4}$ over LSM and Pd/LSM-x $(X=1,2$ and 3) catalysts.

The conversion of $\mathrm{CH}_{4}$ over the Pd/LSM-3 catalyst under different space velocity was also tested and shown in Fig. 7. It is clear that the increase of space velocity only resulted in a certain extent decrease in the activity, but the catalysts could also show over $80 \%$ conversion of $\mathrm{CH}_{4}$ at $550{ }^{\circ} \mathrm{C}$ under a rather high space velocity of $424 \mathrm{~h}^{-1}$, suggesting that $\mathrm{Pd} / \mathrm{LSM}-\mathrm{x}$ catalyst can be highly resistant to large space velocity. The long-term reaction stability of Pd/LSM-3 catalyst was investigated at $550{ }^{\circ} \mathrm{C}$ presented in Fig. 8. The slight differences for the conversions of $\mathrm{CH}_{4}$ can be clearly observed with increasing time on stream over the Pd/LSM-3 catalyst. The conversion of $\mathrm{CH}_{4}$ was slightly decrease and still got to about $92 \%$ after 24 h over the $\mathrm{Pd} / \mathrm{LSM}-3$ at $550{ }^{\circ} \mathrm{C}$, which indicates that the $\mathrm{Pd} /$ LSM-3 catalyst is quite stable with high activity under our reaction conditions. For comparison, the activities of Pd/LSM-3 catalyst are largely higher than those reported in literatures ${ }^{1,41,42}$. The $\mathrm{T}_{10 \%}$ reported by Baylet et al. over a series of $1.0 \mathrm{wt} \% \mathrm{Pd} / \mathrm{REF}$ and $\mathrm{Pd} / \mathrm{HCa}$ is found to vary between 420 and $660^{\circ} \mathrm{C}^{41}$. Davide Ferri et al. ${ }^{1}$ reported 


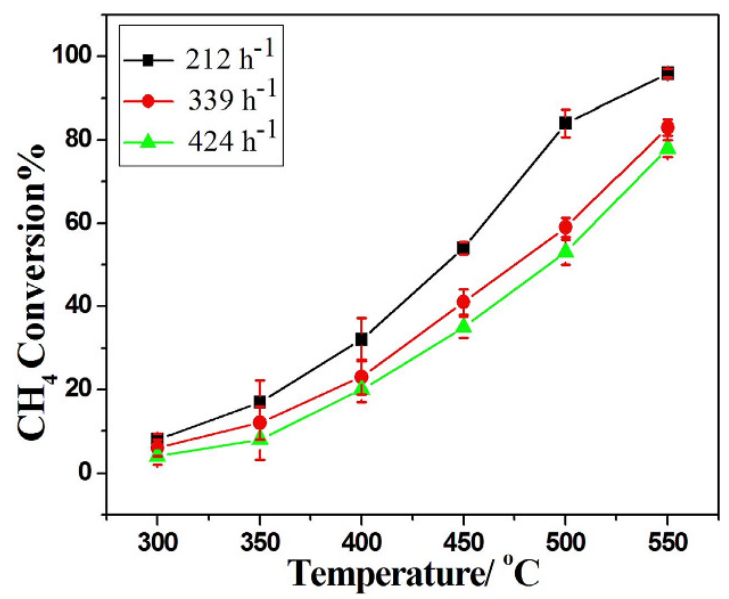

Figure 7. Conversion of $\mathrm{CH}_{4}$ over Pd/LSM-3 catalyst under different GHSV.

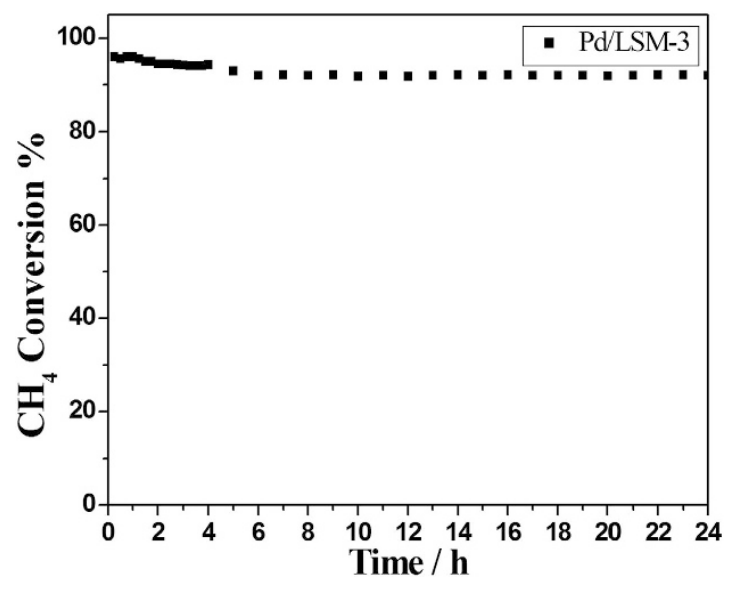

Figure 8. Conversion of $\mathrm{CH}_{4}$ with reaction time over the $\mathrm{Pd} / \mathrm{LSM}-3$ catalyst at $550{ }^{\circ} \mathrm{C}$.

$\mathrm{T}_{10} \%$ for a series of $2 \mathrm{wt} \% \mathrm{Pd} / \mathrm{LaFeO}_{3}-\mathrm{x}\left(\mathrm{x}=300,500,700,1000^{\circ} \mathrm{C}\right.$ calcined $)$ is found to vary between $360^{\circ} \mathrm{C}$ and $520^{\circ} \mathrm{C}$. Similarly, Fernando F.M. et al. ${ }^{42}$ reported $\mathrm{T}_{50} \%$ is higher than $500^{\circ} \mathrm{C}$ for $1 \mathrm{wt} \% \mathrm{Pd} / \mathrm{Gd}_{0.1} \mathrm{Ce}_{0.9} \mathrm{O}_{1.95}$ samples prepared by Incipient wetness impregnation.

The Pd/LSM-x catalysts exhibit much higher activity than the LSM for the $\mathrm{CH}_{4}$ combustion reaction. In $\mathrm{H}_{2}-\mathrm{TPR}$, it can be seen that the amount of adsorbed oxygen in the Pd/LSM-x catalysts is higher than that in LSM catalyst, which is a key activity species in the process of methane combustion. The $\mathrm{O}_{2}$-TPD results also confirm it. The XPS results also agree with the above discussion of $\mathrm{H}_{2}-\mathrm{TPR}$ and $\mathrm{O}_{2}-\mathrm{TPD}$. As we known, the surface adsorbed oxygen species is very active for the oxidation of hydrocarbons at low temperatures ${ }^{12,22}$. A high concentration of the adsorbed oxygen species would be beneficial for enhancement in catalytic activity for the total oxidation of methane ${ }^{12,22}$. In this study, more oxygen vacancies on the surface of Pd/LSM-x catalysts can be generated. This may be the reason of the Pd/LSM-x have a better activity than the LSM sample. It is well known that the catalytic activity for the methane combustion depends strongly on the chemical state of palladium. It is commonly accepted that at low temperature the active phase is crystalline $\mathrm{PdO}$, which may exist in more than one form depending on the oxidized particles size and on the nature of the support, but at high temperature metallic $\mathrm{Pd}$ is the active phase for methane oxidation ${ }^{25}$. In our study, TEM results show the presence of both PdO and Pd phases in the Pd/LSM-x catalysts. The XPS results suggested that the conversion to methane was a function of $\mathrm{Pd}^{2+} / \mathrm{Pd}^{0}$ (Table 2; Fig. 5A). The higher ratio of $\mathrm{Pd}^{2+} / \mathrm{Pd}^{0}$ exists, the better catalytic activity shows. The XPS results show that the ratio of $\mathrm{Pd}^{2+} / \mathrm{Pd}^{0}$ decreases in the order of Pd/LSM-3 $>\mathrm{Pd} / \mathrm{LSM}-2>\mathrm{Pd} / \mathrm{LSM}-1$. So the Pd/LSM-3 exhibits the best activity than the Pd/LSM-2, Pd/LSM-1 and LSM samples.

\section{Conclusion}

The LSM and Pd/LSM-x catalysts were prepared by a facile microwave irradiation method in few minutes. The $\mathrm{Pd} / \mathrm{LSM}-\mathrm{x}$ catalysts exhibit much higher activity than the LSM for the $\mathrm{CH}_{4}$ combustion reactions, meanwhile, the Pd/LSM-3 catalyst with 4.2wt\%Pd shows an excellent catalytic activity and stability for methane combustion, and above $92 \%$ conversion of methane can be kept for $24 \mathrm{~h}$ at $550^{\circ} \mathrm{C}$. It can be attributed to the high ratio of $\mathrm{Pd}^{2+}$ to $\mathrm{Pd}^{0}$ and more surface oxygen vacancy sites, which more easily for $\mathrm{CH}_{4}$ adsorption and oxidation of $\mathrm{CH}_{4}$. 


\begin{abstract}
Methods
Preparation of Catalysts. $\quad \mathrm{La}_{0.8} \mathrm{Sr}_{0.2} \mathrm{MnO}_{3.15}$ was prepared by microwave irradiation process method (MIM). Aqueous solution of nitrates were used as starting materials $\left(\mathrm{Mn}\left(\mathrm{NO}_{3}\right)_{2}, \mathrm{La}\left(\mathrm{NO}_{3}\right)_{3} \cdot 6 \mathrm{H}_{2} \mathrm{O}, \mathrm{Sr}\left(\mathrm{NO}_{3}\right)_{2}\right)$. A typical process was as follows: lanthanum nitrate $(1.4805 \mathrm{~g})$, strontium nitrate $(0.1809 \mathrm{~g})$ and manganese nitrate $(1.5296 \mathrm{~g})$ were dissolved in $20 \mathrm{~mL}$ distilled water, under ultrasound irradiation for $30 \mathrm{~min}$, and stirring for $5 \mathrm{~h}$ at $40^{\circ} \mathrm{C}$. The resulting solution was subjected to microwave irradiation in a simple domestic oven (LWMC-201 China) operating at $2.45 \mathrm{GHz}$ with a maximum power of $650 \mathrm{~W}$ for $6 \mathrm{~min}$.

$\mathrm{Pd} / \mathrm{LSM}-\mathrm{x}(\mathrm{x}=1,2$ and 3$)$ catalysts were prepared as theoretical Pd loading of $2 \mathrm{wt} . \%, 4 \mathrm{wt} . \%$ and $6 \mathrm{wt} . \%$, respectively. $\operatorname{LSM}(0.9800 \mathrm{~g}, 0.9600 \mathrm{~g}, 0.9400 \mathrm{~g})$ was impregnated with the aqueous solution of $\mathrm{PdCl}_{2}$ (mass concentration: $1 \% 3.3326 \mathrm{~g}, 6.6652 \mathrm{~g}, 9.9978 \mathrm{~g})$ using the incipient wetness technique. Ethylene glycol $(60 \mathrm{~mL}, 120 \mathrm{~mL}$, $360 \mathrm{~mL}$ ) was reducing agent, and ammonia was precipitant. The obtained solution was stirring for $24 \mathrm{~h}$ at $40^{\circ} \mathrm{C}$, and the resulting solution was subjected to microwave irradiation in a operating with a maximum power of $650 \mathrm{~W}$ for $2 \mathrm{~min}$. Chloride anions are considered as a poison for Pd/LSM catalysts, so a wash step after heat is necessary to get chloride anions eliminated. After washing and filtration, the precipitates were dried at $100^{\circ} \mathrm{C}$.
\end{abstract}

Characterization of Catalysts. X-ray diffraction (XRD) patterns were obtained with a D/MAX-3B X-ray Diffractometer (Rigaku Co.), using $\mathrm{Cu} \mathrm{K \alpha}$ radiation combined with a Ni-filter. BET surface area was derived from $\mathrm{N}_{2}$ adsorption-desorption isotherms at $77 \mathrm{~K}$ with a Micromeritics Tristar II surface area and a porosimetry analyzer. In each case, the catalyst (more than $100 \mathrm{mg}$ ) was degassed under vacuum at $150^{\circ} \mathrm{C}$ for $5 \mathrm{~h}$ before the measurement. The content of palladium was determined by inductively coupled plasma (ICP) analysis. Transmission electron microscopy (TEM) measurements were taken on a JEM-2100 electron microscope operating at $200 \mathrm{kV}$. Temperature-programmed reduction with hydrogen $\left(\mathrm{H}_{2}\right.$-TPR) were carried out in a full automatic instrument (XQ TP-5080, China) and performed in the following procedure: Firstly, $20 \mathrm{mg}$ of the catalyst was mounted in a quartz tube and calcined under $\mathrm{O}_{2}$ stream $(30 \mathrm{~mL} / \mathrm{min})$ at $200^{\circ} \mathrm{C}$ for $1 \mathrm{~h}$. After the catalyst was cooled down to $25^{\circ} \mathrm{C}$, with a $30 \mathrm{~mL} / \mathrm{min}$ stream of reduction gas (mixed $5 \% \mathrm{H}_{2}$ and $95 \% \mathrm{~N}_{2}$ ), the reactor was carried out by raising the temperature from 20 to $900^{\circ} \mathrm{C}$ at a rate of $10^{\circ} \mathrm{C} / \mathrm{min}$. Temperature-programmed desorption of oxygen $\left(\mathrm{O}_{2}\right.$-TPD) were carried out in the same automatic instrument of $\mathrm{H}_{2}$-TPR and the procedure was performed as follows: firstly, $100 \mathrm{mg}$ of the catalyst was mounted in a quartz tube and calcined under a helium stream $(20 \mathrm{~mL} /$ $\min$ ) at $200^{\circ} \mathrm{C}$ for $1 \mathrm{~h}$, then pure $\mathrm{O}_{2}$ was introduced into the system at the rate of $20 \mathrm{~mL} / \mathrm{min}$ for $1 \mathrm{~h}$. After the catalyst was cooled down to $25^{\circ} \mathrm{C}$, the catalyst was flushed in $\mathrm{He}$ flow $(20 \mathrm{~mL} / \mathrm{min})$ to remove physisorbed $\mathrm{O}_{2}$ at $25^{\circ} \mathrm{C}$. Finally, the sample was gradually heated from $25^{\circ} \mathrm{C}$ to $900^{\circ} \mathrm{C}$ at a ramp of $10^{\circ} \mathrm{C} / \mathrm{min}$. X-ray photoelectron spectroscopy (XPS) was recorded on a Thermo ESCALAB 250 spectrometer using a monochromatic AlK $\alpha$ X-ray source $(15 \mathrm{KV}, 150 \mathrm{~W})$ and analyzer pass energy of $100 \mathrm{eV}$. Binding energies (BE) are referenced to the $\mathrm{C}(1 \mathrm{~s})$ binding energy of carbon taken to be $284.7 \mathrm{eV}$.

Catalytic evaluation. $\mathrm{CH}_{4}$ oxidation was carried out with a fixed-bed reactor with a $6 \mathrm{~mm}$-diameter glass tube, $0.100 \mathrm{~g}$ of the catalyst (40-60 mesh) was set in the reactor by using quartz wool, gaseous mixtures of $\mathrm{CH}_{4} /$ $\mathrm{O}_{2} / \mathrm{N}_{2}=1 / 4 / 95$ were fed to the catalyst bed after being blended at a rate of $25 \mathrm{~mL} / \mathrm{min}$. The gas composition was analyzed before and after the reaction by an online gas chromatography using TDX-01 column $(2 \mathrm{~m} \times 3 \mathrm{~mm})$. The activity of $\mathrm{CH}_{4}$ oxidation reaction was evaluated by the following equation:

$\mathrm{CH}_{4}$ conversion $\%=\left\{\left[\mathrm{CH}_{4}\right]_{\text {in }}-\left[\mathrm{CH}_{4}\right]_{\text {out }}\right\} /\left[\mathrm{CH}_{4}\right]_{\text {in }} \times 100 \%$.

\title{
References
}

1. Eyssler, A. et al. Influence of thermally induced structural changes of $2 \mathrm{wt} \% \mathrm{Pd} / \mathrm{LaFeO}_{3}$ on methane combustion activity. Appl. Catal. $B$ 106, 494-502 (2011).

2. Gélin, P. \& Primet, M. Complete oxidation of methane at low temperature over noble metal based catalysts: a review. Appl. Catal. B 39, 1-37 (2002).

3. Choudhary, T. V., Banerjee, S. \& Choudhary, V. R. Catalysts for combustion of methane and lower alkanes. Appl. Catal. A 234, 1-23 (2002).

4. Atsushi, S., Takumi, T., Kohei, O. \& Yuta, Y. Effect of preparation method of Co-promoted Pd/alumina for methane combustion. Catal. Today 242, 308-314 (2015).

5. Park, J. H., Cho, J. H., Kim, Y. J. \& Kim, E. S. Hydrothermal stability of $\mathrm{Pd} / \mathrm{ZrO}_{2}$ catalysts for high temperature methane combustion. Appl. Catal. B 160-161, 135-143 (2014)

6. Jiang, Z., Yu, J. J., Cheng, J., Jones, M. O. \& Edwards, P. P. Catalytic combustion of methane over mixed oxides derived from Co-Mg/ Al ternary hydrotalcites. Fuel Process. Technol. 91, 97-102 (2010).

7. Qiao, D. S. et al., Effect of Ca doping on the catalytic performance of $\mathrm{CuO}-\mathrm{CeO}_{2}$ catalysts for methane combustion. Catal Commun. 11, 858-861 (2010).

8. Vegten, N. V., Baidya, T. K., Krumeich, F., Kleist, W. \& Baiker, A. Flame-made $\mathrm{MgAl}_{2-\mathrm{x}} \mathrm{M}_{\mathrm{x}} \mathrm{O}_{4}(\mathrm{M}=\mathrm{Mn}, \mathrm{Fe}, \mathrm{Co})$ mixed oxides: Structural properties and catalytic behavior in methane combustion. Appl. Catal. B 97, 398-406 (2010).

9. Wang, Z. J., Liu, Y., Shi, P., Liu, C. J. \& Liu, Y. Al-MCM-41 supported palladium catalyst for methane combustion: Effect of the preparation methodologies. Appl. Catal. B 90, 570-577 (2009).

10. Pena, M. A. \& Fierro, J. L. Chemical structures and performance of perovskite oxides. Chem. Rev. 101, 1981-2017 (2001).

11. Li, Y. C., Wang, C. L. \& Li, C. L. Pd-integrated lanthanum-transition metal perovskites for methanol partial oxidation. Catal. Today 174, 135-140 (2011).

12. Zhu, J. et al. Perovskite oxides: preparation, characterizations, and applications in heterogeneous catalysis. ACS Catal . 4, 2917-2940 (2014).

13. Kremenić, G., Nieto, J. M. D., Tascón, J. M. D. \& Tejuca, L. G. K. Chemisorption and catalysis on $\mathrm{LaMO}_{3}$ oxides. J. Chem. Soc., Faraday Trans. 81, 939-949 (1985).

14. Nitadori, T., Ichiki, T. \& Misono, M. Catalytic Properties of Perovskite-Type Mixed Oxides $\left(\mathrm{ABO}_{3}\right)$ Consisting of Rare Earth and $3 \mathrm{~d}$ Transition Metals. The Roles of the A- and B-Site Ions. Bull. Chem. Soc. Jpn. 61, 621-626 (1988).

15. Agarwal, D., D. \& Goswami, H. S. Toluene oxidation on $\mathrm{LaCoO}_{3}, \mathrm{LaFeO}_{3}$ and $\mathrm{LaCrO}_{3}$ perovskite catalysts a comparative study. React. Kinet. and Catal. Lett. 53, 441-449 (1994) 
16. Levasseur, B. \& Kaliaguine, $\mathrm{S}$. Methanol oxidation on $\mathrm{LaBO}_{3}(\mathrm{~B}=\mathrm{Co}, \mathrm{Mn}, \mathrm{Fe})$ perovskite-type catalysts prepared by reactive grinding. Appl. Catal. A 343, 29-38 (2008).

17. Faye, J., Tatibouët, J. M., Baylet, A., Trentesaux, M. \& Royer, S. Influence of lanthanum stoichiometry in $\mathrm{La}_{1-\mathrm{x}} \mathrm{FeO}_{3-\delta}$ perovskites on their structure and catalytic performance in $\mathrm{CH}_{4}$ total oxidation. Appl. Catal. B 126, 134-143 (2012).

18. Ponce S., Pena, M. A. \& Fierro, J. L. G. Surface properties and catalytic performance in methane combustion of Sr-substituted lanthanum manganites. Appl. Catal. B 24, 193-205 (2000).

19. Deng, J. G., Zhang, L., Dai, H. X., He, H. \& Au, C. T. Hydrothermally fabricated single-crystalline strontium- substituted lanthanum manganite microcubes for the catalytic combustion of toluene. J. Mater. Chem. A 299, 60-67 (2009).

20. Niu, J. R. et al. Nanosized perovskite-type oxides $\mathrm{La}_{1-\mathrm{x}} \mathrm{Sr}_{\mathrm{x}} \mathrm{MO}_{3-\delta}(\mathrm{M}=\mathrm{Co}, \mathrm{Mn} ; \mathrm{x}=0,0.4)$ for the catalytic removal of ethylacetate, Catal. Today 126, 420-429 (2007).

21. Chenakin, S. P., Melaet, G., Szukiewicz, R. \& Kruse, N. XPS study of the surface chemical state of a $\mathrm{Pd} /\left(\mathrm{SiO}_{2}+\mathrm{TiO}_{2}\right)$ catalyst after methane oxidation and $\mathrm{SO}_{2}$ treatment. J. Catal. 312, 1-11 (2014).

22. Royer, S., Duprez, D., Can, F., Courtois, X. \& Alamdari, H. Perovskites as substitutes of noble metals for heterogeneous catalysis: dream or reality., Chem. Rev. 114, 10292-10368 (2014).

23. Martin, S. et al. Methane oxidation-effect of support, precursor and pretreatment Conditions-in situ reaction XPS and DRIFT. Catal. Today 118, 392-401 (2006).

24. Gélin, P. \& Primet, M. Complete oxidation of methane at low temperature over noble metal based catalysts: a review Appl. Catal. B 39 1-37 (2002).

25. Kaden, W. E., Wu, T., Kunkel, W. A. \& Anderson, S. L. Electronic Structure Controls Reactivity of Size-Selected Pd Clusters Adsorbed on $\mathrm{TiO}_{2}$. Surf. Sci. 326, 826-829 (2009).

26. Farrauto, R. J., Lampert, J. K., Hobson, M. C. \& Waterman, E. M. Thermal decomposition and reformation of PdO catalysts; support effects. Appl. Catal. B 6 263-270 (1995).

27. Iglesia, E., Avalos-Borja, M., Fujimoto, K. \& Ribeiro, F. H. Structure and reactivity of $\mathrm{PdOx} / \mathrm{ZrO}_{2}$ catalysts for methane oxidation at low temperatures. J. Catal. 179, 431-442 (1998).

28. Gao, D. N., Zhang, C. N., Wang, S., Yuan, Z. S. \& Wang, S. D. Catalytic activity of $\mathrm{Pd} / \mathrm{Al}_{2} \mathrm{O}_{3}$ toward the combustion of methane. Catal. Commun. 9, 2583-2587 (2008)

29. Farrauto, R. P., Hobson, M. C., Kennelly, T. \& Waterman, E. M. Catalytic chemistry of supported palladium for combustion of methane. Appl. Catal. A. 81, 227-237 (1992).

30. Cimino, S., Casaletto, M. P., Lisi, L. \& Russo, G. Pd-LaMnO 3 as dual site catalysts for methane combustion. Appl. Catal. A 327, 238-246 (2007)

31. Arandiyan, H., Li. J. H., Ma, L., Hashemnejad, S. M. \& Chen L. Methane reforming to syngas over $\mathrm{LaNi}_{\mathrm{x}} \mathrm{Fe}_{1-\mathrm{x}} \mathrm{O}_{3}(0 \leq \mathrm{x} \leq 1)$ mixedoxide perovskites in the presence of $\mathrm{CO}_{2}$ and $\mathrm{O}_{2}$, Ind. Eng. Chem. Res. 18, 2103-2114 (2012).

32. Prasad, D. H. et al. Synthesis of nano-crystalline $\mathrm{La}_{1-\mathrm{x}} \mathrm{Sr}_{\mathrm{x}} \mathrm{CoO}_{3-\delta}$ perovskite oxides by EDTA-citrate complexing process and its catalytic activity for soot oxidation. Appl. Catal. A 447-448, 100-106 (2012).

33. Huang, L. H., Zhang, F. B., Wang, N., Chen, R. R. \& Hsu, A. T. Nickel-based perovskite catalysts with iron-doping via selfcombustion for hydrogen production in auto-thermal reforming of Ethanol. Int. J. Hydrogen. Energy 37, 1271-1279 (2012).

34. Rezaei, M. et al. Autothermal reforming of methane over $\mathrm{Ni} \mathrm{catalysts} \mathrm{supported} \mathrm{on} \mathrm{nanocrystalline} \mathrm{MgO}$ with high surface area and plated-like shape. Int. J. Hydrogen. Energy 36, 11712-11717 (2011).

35. Liao, X. H., Zhu, J. M., Zhu, J. J., Xu, J. Z. \& Chen, H. Y. Preparation of monodispersed nanocrystalline $\mathrm{CeO}_{2}$ powders by microwave irradiation. Chem. commun. 24, 937-938 (2001).

36. Ran, R., Weng, D., Wu, X. D., Fan, J. \& Qing, L. Rapid synthesis of $\mathrm{La}_{0.7} \mathrm{Sr}_{0.3} \mathrm{MnO}_{3+\lambda}$ catalysts by microwave irradiation process. Catal. Today 126, 394-399 (2007).

37. Zhu, Y. J., Sun, Y. Q., Niu, X. Y., Yuan, F. L. \& Fu, H. G. Preparation of La-Mn-O perovskite catalyst by microwave irradiation method and its application to methane combustion. Catal. Lett. 135, 152-158 (2010).

38. Guo, X. N. et al. Methane combustion over $\mathrm{Pd} / \mathrm{ZrO}_{2} / \mathrm{SiC}, \mathrm{Pd} / \mathrm{CeO}_{2} / \mathrm{SiC}$, and $\mathrm{Pd} / \mathrm{Zr}_{0.5} \mathrm{Ce}_{0.5} \mathrm{O}_{2} / \mathrm{SiC}$ catalysts. Catal. Commun. 12, 870-874 (2011).

39. Kim, S. K. et al. Performance of shape-controlled Pd nanoparticles in the selective hydrogenation of acetylene. J. Catal. 306, 146-154 (2013).

40. Arandiyan, $\mathrm{H}$. et al. Three-dimensionally ordered macroporous $\mathrm{La}_{0.6} \mathrm{Sr}_{0.4} \mathrm{MnO}_{3}$ with high surface areas: Active catalysts for the combustion of methane. J. Catal. 307, 327-339 (2013).

41. Baylet, A., Royer, S., Marecot, P., Tatibouet, J. M. \& Duprez, D. Effect of Pd precursor salt on the activity and stability of Pd-doped hexaaluminate catalysts for the $\mathrm{CH}_{4}$ catalytic combustion. Appl. Catal. B 81 88-96 (2008).

42. Fernando, F. M., Richard, T. B. \& Rodolfo, O. F. Reduction and catalytic behaviour of nanostructured Pd/gadolinia-doped ceria catalysts for methane combustion. Appl. Catal. B 136-137 122-132 (2013).

\section{Acknowledgements}

This work is supported by Natural Sciences Fund of Heilongjiang Province (B2015009), Foundation of Educational Commission of Heilongjiang Province of China (11531286), Postdoctoral Science-research Developmental Foundation of Heilongjiang Provine of China (LBH-Q12022), Innovative Research Team in Heilongjiang University (Hdtd2010-10) and Program for Innovative Research Team in University (IRT-1237). The Project sponsored by SRF for ROCS, SEM (2013-1792) and Ministry of Human Resources and Social Security $(2013-277)$

\section{Author Contributions}

W.W. performed the experimental works, analyzed results. F.Y. and X.N. assisted in the analyses of results. Y.Z. proposed, planned, and designed the project and reviewed the manuscript prior to submission. All authors wrote the manuscript.

\section{Additional Information}

Supplementary information accompanies this paper at http://www.nature.com/srep

Competing financial interests: The authors declare no competing financial interests.

How to cite this article: Wang, W. et al. Preparation of Pd supported on La(Sr)-Mn-O Perovskite by microwave Irradiation Method and Its Catalytic Performances for the Methane Combustion. Sci. Rep. 6, 19511;

doi: 10.1038/srep19511 (2016). 
(c) (i) This work is licensed under a Creative Commons Attribution 4.0 International License. The images or other third party material in this article are included in the article's Creative Commons license, unless indicated otherwise in the credit line; if the material is not included under the Creative Commons license, users will need to obtain permission from the license holder to reproduce the material. To view a copy of this license, visit http://creativecommons.org/licenses/by/4.0/ 